\title{
A Deep-Sequencing Method Detects Drug-Resistant Mutations in the Hepatitis B Virus in Indonesians
}

\author{
Dewiyani Indah Widasaria, e Yoshihiko Yano ${ }^{a}{ }^{a b}$ Didik Setyo Heriyanto ${ }^{e}$ \\ Takako Utsumi ${ }^{a, f}$ Laura Navika Yamani ${ }^{a, f}$ Hanggoro Tri Rinonce ${ }^{a, e}$

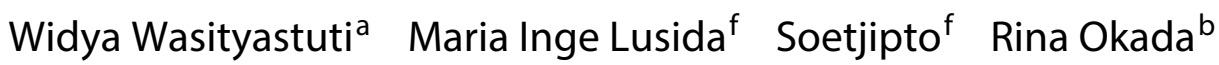 \\ Yoshiki Murakami $^{d}$ Toshihito Tanahashi $^{b, c}$ Takeshi Azuma ${ }^{b}$ \\ Yoshitake Hayashi ${ }^{\mathrm{a}}$ \\ ${ }^{a}$ Center for Infectious Diseases and ${ }^{b}$ Department of Gastroenterology, Kobe University Graduate School of \\ Medicine, and ' Department of Medical Pharmaceutics, Kobe Pharmaceutical University, Kobe, and d Department

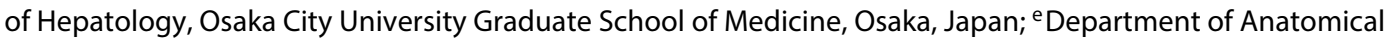 \\ Pathology, Faculty of Medicine, Dr. Sardjito Hospital, Gadjah Mada University, Yogyakarta, and $\mathrm{f}_{\text {Indonesia-Japan }}$ \\ Collaborative Research Center for Emerging and Re-emerging Infectious Diseases, Institute of Tropical Disease, \\ Airlangga University, Surabaya, Indonesia
}

\section{Key Words}

Hepatitis B virus · Deep sequencing · Nucleos(t)ide analogue $\cdot$ Indonesia

\begin{abstract}
Objective: The long-term administration of a nucleos(t)ide analogue (NA) for the treatment of chronic hepatitis B may encourage the emergence of viral mutations associated with drug resistance. Minor populations of viruses may exist before treatment, but are difficult to detect because of technological limitations. Identifying minor viral quasispecies should be useful in the clinical management of hepatitis $B$ virus (HBV) infection. Methods: Six treatment-naïve Indonesian patients with chronic HBV infection participated in this study. The polymerase region of the HBV genome,
\end{abstract}

including regions with known drug-resistant mutations, was subjected to capillary sequencing and MiSeq sequencing (Illumina). Mutations were analyzed with Genomics Workbench software version 6.0.1 (CLC bio). Results: The mean mapping reads for the six samples was 745,654 , and the mean number of amplified fragments ranged from 17,926 to 25,336 DNA reads. Several known drug-resistant mutations in the reverse transcriptase region were identified in all patients, although the frequencies were low $(0.12$ $1.06 \%)$. The proportions of the total number of reads containing mutations $1169 \mathrm{~L} / \mathrm{M}, \mathrm{S} 202 \mathrm{R}, \mathrm{M} 204 \mathrm{I} / \mathrm{L}$ or N236S were $>1.0 \%$. Conclusion: Several known NA-resistant mutations were detected in treatment-naïve patients in Indonesia using deep sequencing. Careful management of such patients is essential to prevent drug-resistant mutations from spreading to other patients.

\section{KARGER}

E-Mail karger@karger.com

www.karger.com/int
(C) 2014 S. Karger AG, Basel

0300-5526/14/0576-0384\$39.50/0
Yoshihiko Yano, MD, $\mathrm{PhD}$

Center for Infectious Diseases, Kobe University Graduate School of Medicine

7-5-1 Kusunoki-cho, Chuo-ku

Kobe 650-0017 (Japan)

E-Mail yanoyo@med.kobe-u.ac.jp 


\section{Introduction}

Approximately 350 million people are infected with hepatitis B virus (HBV) worldwide, including asymptomatic carriers, making HBV infection a major global health problem. Chronic HBV infection often progresses to liver cirrhosis and hepatocellular carcinoma, and around 1 million deaths per year are thought to be related to $\mathrm{HBV}$ infection [1]. The prevalence of $\mathrm{HBV}$ infection varies considerably between countries. In Indonesia, it is reported that $4.0-20.3 \%$ of the population are infected with $\mathrm{HBV}$, and Indonesia is considered to be a moderate-tohigh endemic region [2].

The purpose of chronic hepatitis $\mathrm{B}(\mathrm{CHB})$ therapy is the sustained suppression of HBV replication and the remission of liver disease. The nucleos $(\mathrm{t})$ ide analogues (NAs) used to treat CHB include lamivudine (LAM), telbivudine (L-deoxythymidine; LdT), entecavir (ETV), adefovir dipivoxil (ADV), tenofovir and emtricitabine. NAs mainly suppress viral proliferation by inhibiting HBV DNA polymerase activity. They are generally well tolerated and are easy to administer once daily. They also reduce liver damage, improve liver function and inhibit hepatocarcinogenesis in chronically HBV-infected patients with fewer adverse effects than conventional interferon therapy $[3,4]$. However, the emergence of drug-resistant mutations during long-term treatment is a major limitation of these drugs. Drug-resistant mutations were found in approximately $70 \%$ of patients treated with LAM for up to 5 years and in $3 \%$ of patients treated with ADV for up to 3 years. Resistance to ETV was reported in $1.1 \%$ of patients treated for up to 4 years [5-7]. Numerous cases of severe reactivation, viral relapse and exacerbation of hepatitis after discontinuation of NA therapy have also been reported [8].

The HBV genome is a partially double-stranded circular DNA molecule of approximately 3,200 bp, consisting of four overlapping open reading frames that encode the surface protein, the core protein, a polymerase and region $\mathrm{X}$, which encodes a multifunctional nonstructural protein. The polymerase region is an important target for NAs, and mutations in this region are sometimes associated with drug resistance. HBV replication is very fast, with up to $10^{11}$ viral particles released per day. This high replication rate, coupled to the absence of a proofreading mechanism in the HBV polymerase, contributes to the appearance of mutations $[9,10]$. Mutations in the reverse transcriptase (RT) region sometimes induce viral breakthrough. These mutations include drug-induced mutations after NA treatment, and natural mutations or viral quasispecies present prior to treatment $[3,5]$.

HBV Mutations Detected by Deep

Sequencing
However, it is currently very difficult to detect viruses with drug-resistant mutations that are present in very low copy numbers because of technological limitations. Nextgeneration sequencing methods are used to sequence thousands to millions of sequences concurrently, allowing us to detect any preexisting mutations before antiviral therapy is commenced. Identifying minor viral quasispecies and low-frequency NA-resistant mutations in treatment-naive patients should allow us to select the most appropriate NA regimen and to predict the future emergence of mutations, offering significant benefits in the management of patients with HBV infection. Although some studies have used next-generation sequencing methods to detect NA-resistant mutations, most of the patients had HBV genotype C $[11,12]$.

In this study, we sought to identify quasispecies in the $\mathrm{RT}$ region of the HBV genome and detect possible drugresistant mutations in Indonesian treatment-naïve patients with $\mathrm{CHB}$, using a next-generation sequencer. The results are expected to be useful for evaluating the risk of emerging drug-resistant mutations and selecting the most appropriate antiviral drug for patients with $\mathrm{CHB}$.

\section{Materials and Methods}

\section{Subjects}

To detect preexisting mutations associated with NA resistance in Indonesian patients, we obtained serum samples at the inpatient and outpatient units of the Gastroenterology and Hepatology Department of Internal Medicine, Dr. Sardjito Hospital, Yogyakarta, Indonesia, from 6 treatment-naïve chronic HBV carriers. The patients were 22-77 years old (median 38 years). Three of the patients were asymptomatic carriers and the other 3 had advanced liver disease: hepatocellular carcinoma in 2 and liver cirrhosis in 1. Alanine aminotransferase and aspartate aminotransferase levels were measured immediately after blood collection. Informed consent was obtained from all of the patients. The study was approved by the Medical and Health Ethics Committees of Gadjah Mada University and Kobe University (Japan).

DNA Extraction and Measurement of the HBV Viral Load

HBV DNA was extracted from $200 \mu \mathrm{l}$ of sera using a Qiagen DNA Blood Mini Kit, according to the manufacturer's instructions (Qiagen, Tokyo, Japan). The HBV viral load was measured with real-time polymerase chain reaction (PCR) on an ABI Prism 7700 Genetic Analyzer (Applied Biosystems, Foster City, Calif., USA), using a previously described specific primer and probe set [13].

\section{Direct PCR Sequencing and Genotype Determination}

The RT region was amplified and confirmed with a PCR assay using specific primers [14]. After the first round of PCR with the HB8F and HB6R primers, a nested PCR was performed with the HB2F and HB3R primers. The amplified products (694 bp) ob- 
Table 1. Clinical characteristics of patients and results of next-generation sequencing

\begin{tabular}{|c|c|c|c|c|c|c|}
\hline & \multicolumn{6}{|l|}{ Patient ID } \\
\hline & B55 & B77 & B149 & B13 & B126 & B143 \\
\hline Sex & male & male & female & male & female & male \\
\hline Diagnosis & $\mathrm{AC}$ & $\mathrm{AC}$ & $\mathrm{AC}$ & $\mathrm{HCC}$ & $\mathrm{HCC}$ & cirrhosis \\
\hline Viral load, log copies/ml & 7.7 & 7.7 & 2.7 & $<2.6$ & $<2.6$ & 3.9 \\
\hline$\gamma$-GTP, IU/l & 40 & 27 & 17 & 8 & 19 & 30 \\
\hline Genotype & B3 & B3 & B3 & B3 & B3 & B3 \\
\hline Total reads & $1,781,062$ & $1,327,708$ & $1,638,654$ & $1,260,250$ & $1,298,306$ & $1,413,446$ \\
\hline Mapping reads & 914,396 & 679,886 & 837,533 & 648,284 & 667,297 & 726,531 \\
\hline Mean coverage per nucleotide & 25,336 & 18,191 & 23,372 & 17,926 & 18,519 & 20,589 \\
\hline
\end{tabular}

$\mathrm{AC}=$ Asymptomatic carrier; $\mathrm{HCC}=$ hepatocellular carcinoma; AST $=$ aspartate aminotransferase; $\gamma$-GTP $=\gamma$-glutamyl transpeptidase.

tained with the nested PCR were directly sequenced using a Taq Dye Deoxy Terminator Cycle Sequencing Kit on an ABI Prism ${ }^{\circledR}$ 3100-Avant Genetic Analyzer (Applied Biosystems). The HBV genotypes were determined using a phylogenetic tree of the $S$ region. Reference sequences were retrieved from the Japan/ European Molecular Biology Laboratory, and GenBank DNA databases. Sequences were aligned using ClustalX software (www. clustal.org). Phylogenetic trees were constructed using the neighbor-joining method and bootstrap resampling was performed 1,000 times. The analyses were conducted with Molecular Evolutionary Genetics Analysis (MEGA) software [15].

\section{PCR Products and Short-Read Sequencing}

The concentration of each nested PCR product (694 bp) was measured using a Qubit dsDNA HS Assay Kit (Q32851; Invitrogen, Carlsbad, Calif., USA). A library of PCR products ( $<500 \mathrm{bp})$ of the viral genome (50 or $0.2 \mathrm{ng}$ ) was prepared using Nextera DNA Sample Prep Kit (Illumina, San Diego, Calif., USA) or Nextera XT DNA Sample Prep Kit (Illumina), according to the manufacturer's instructions. The PCR products were uniformly sheared into 500-bp fragments using these kits and the PCR product libraries were mixed with $1 \% 8 \mathrm{pM}$ PhiX as controls, and then run on a MiSeq sequencer (Illumina) for paired-end 151-bp sequencing. The fluorescent images were analyzed using the MiSeq control software and reporter analysis (Illumina) to obtain FASTQ-formatted sequence data.

\section{Sequence Read Mapping and Data Analysis}

In accordance with the recommendation of Illumina, the sequences were used when the read quality estimated by the Q30 (quality score 30 ) was over $80 \%$ of the consensus sequence. After a quality check and data trimming, Genomics Workbench software version 6.0.1 (CLC bio, Aarhus, Denmark) was used to assemble the sequences. Sequence reads were mapped against the reference HBV genome (AB713528). Single-nucleotide polymorphisms were identified with probabilistic variant detection modules using the default parameters in the mapping algorithm.
The characteristics of the viral quasispecies were evaluated in terms of their genetic complexity based on the number of different sequences present in the population. To achieve this, we used the setting 'read conflicts' in Genomic Workbench. When mapping was completed, conflicts between the sequence reads were annotated on the consensus sequence. The definition of a conflict is a position at which at least one of the sequence reads encodes a different nucleotide.

\section{Statistical Analysis}

Continuous variables were compared with Student's t test or analysis of variance. $\mathrm{p}<0.05$ was considered statistically significant. Statistical analyses were performed using SPSS software version 18.0 (SPSS Inc., Chicago, Ill., USA).

\section{Results}

\section{RT Genome Alignment}

The characteristics of the subjects enrolled in this study are summarized in table 1 . We sequenced and analyzed part (encoding amino acids 119-306) of the RT region. Figure 1 shows the deduced protein sequence alignment of the six samples obtained with the direct-sequencing method. The capillary-sequencing method detected no drug-resistant mutations. The phylogenetic tree revealed that all samples examined in this study belonged to genotype B3 (fig. 2).

\section{NA-Resistant Mutations Detected with \\ Next-Generation Sequencing}

The number of mapping reads in the six samples ranged from 648,284 to 914,396, and the coverage 


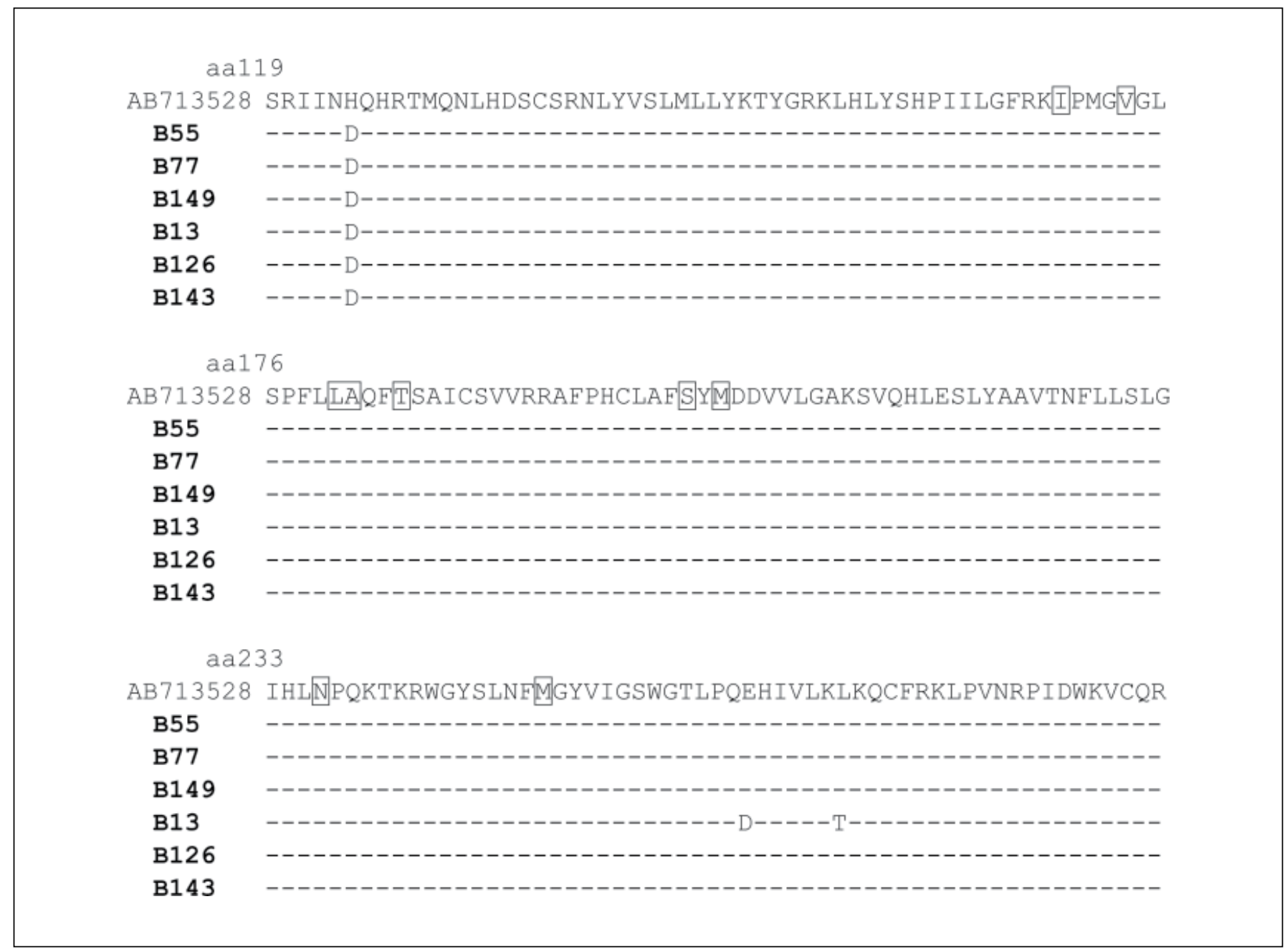

Fig. 1. Amino acid sequence alignment of the RT region of the HBV genome. The amino acid sequences were obtained by direct sequencing. The amino acid sequences obtained for the Indonesian treatment-naïve patients in this study (bold) were

ranged from 17,926 to 25,366 (table 1). Preexisting NAresistant mutations in nine known positions of the RT region (rt169, rt173, rt180, rt181, rt184, rt202, rt204, rt236 and rt250) were detected in all 6 patients, although the frequencies of these mutations were low (0.12-1.06\%). The frequencies of the amino acid substitutions M204I (conferring resistance to LAM/ETV), A181T (to LAM/ADV), A181V (to ADV) and T184A (to ETV) ranged from 0.91 to $1.06 \%$, and were greater than those of the other amino acid substitutions. The frequencies of M204V (conferring resistance to LAM/ ETV), S202G (to ETV), T184S (to ETV), N236T (to $\mathrm{ADV}$ ) and M250V (to ETV) ranged from 0.48 to $0.69 \%$. compared with those of other Indonesian isolates (top row). The residues within squares show the nine known positions of the NA resistance (rt169, rt173, rt180, rt181, rt184, rt202, rt204, rt236 and rt250).
The frequencies of the LAM/ETV-resistant substitutions $\mathrm{L} 180 \mathrm{M}$ and $\mathrm{I} 169 \mathrm{~T}$ ranged from 0.12 to $0.2 \%$ (table 2).

The next-generation sequencing method also revealed several other substitutions with frequencies $\geq 1 \%$ : I169M, I169L, V173A, S202R, M204L and N236S (table 3). These mutations have not previously been reported to be associated with NA resistance. Statistical analysis revealed that the prevalence of preexisting NA-resistant mutations was not significantly different between the chronic asymptomatic patients and the patients with advanced liver disease (table 4). 
Fig. 2. Neighbor-joining phylogenetic tree for HBV strains in Indonesian treatmentnaïve patients (indicated with solid circles). The phylogenetic analysis was carried out based on $694 \mathrm{bp}$ of the partial S region. The bootstrap support for the consensus tree, inferred from 1,000 replicates, is indicated for each branch. The evolutionary distances were computed using the maximum composite likelihood method.

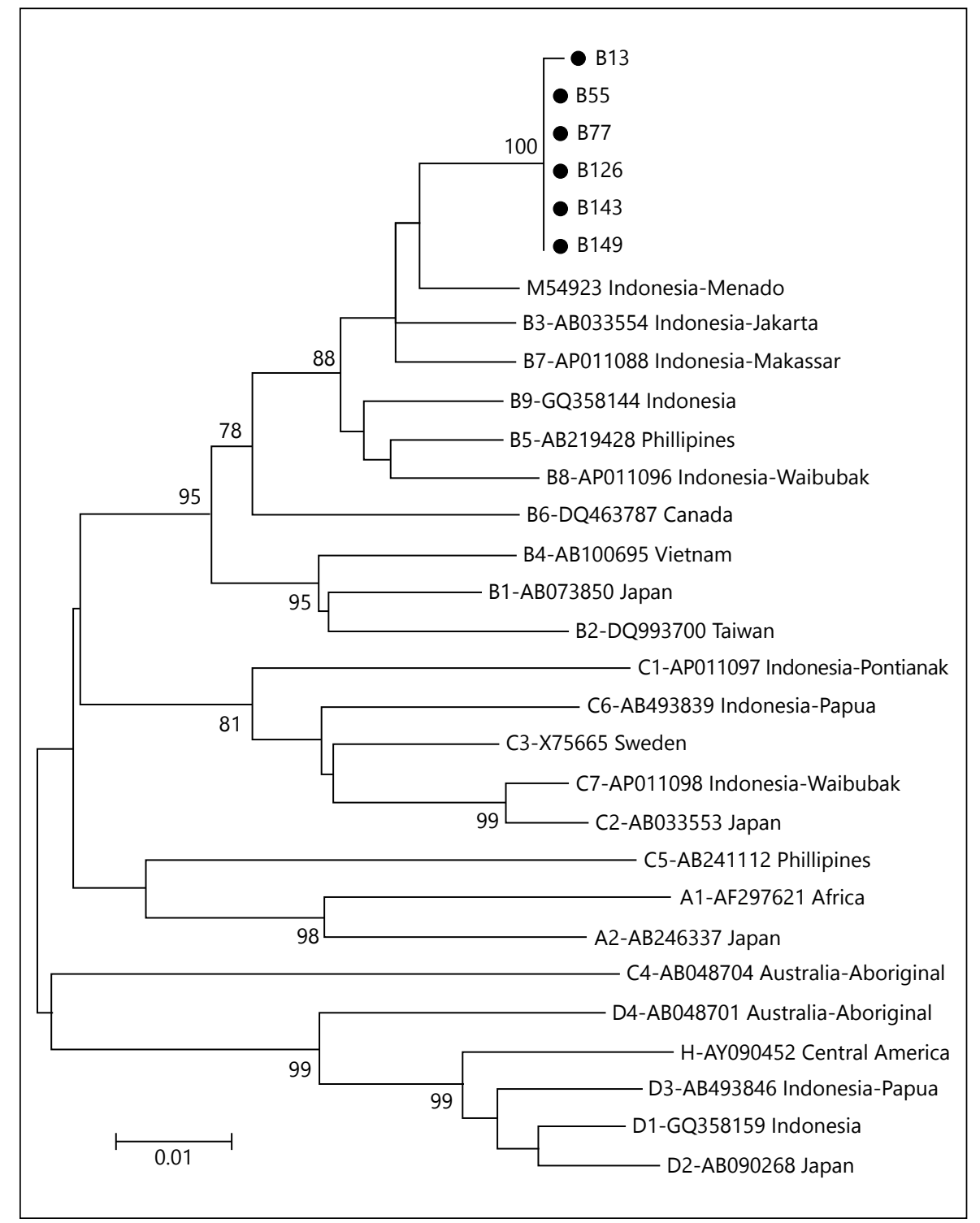

\section{Discussion}

The emergence of drug resistance is a serious problem during treatment with NA. The inhibition of HBV replication with NA may lead to the emergence of several mutations that are translated into specific amino acid changes that confer antiviral resistance [16]. Drug-resistant viruses show increased levels of HBV DNA in the liver and blood, a phenomenon known as 'virological breakthrough' or 'clinically induced hepatitis flare' [17]. The presence of genomic quasispecies may facilitate the emergence of multidrug resistance. Several studies have demonstrated the higher relative sensitivity of ultra-deep sequencing compared with conventional direct-population sequencing. Therefore, ultra-deep sequencing is useful for detecting low-frequency drug-resistant mutations that cannot be detected with standard methods [18-21]. Conventional sequencing based on the Sanger method can only detect mutations present in $>20 \%$ of viral quasispecies. Although the line probe assay is another common and convenient method to detect mutations, it can only detect mutations present in $>15 \%$ of viral quasispecies [20]. Cloning-based sequencing methods are also commonly used, but they usually detect less than $50 \%$ of the substitutions identified with ultra-deep sequencing [21]. The relationship between the viral dy- 
Table 2. Known NA-resistant mutations in the RT region of the HBV genome detected with next-generation sequencing

\begin{tabular}{|c|c|c|c|c|c|c|c|c|}
\hline $\begin{array}{l}\text { Position/ } \\
\text { substitution }\end{array}$ & NA resistance & B13 & B55 & B77 & B126 & B143 & B149 & Mean \pm SD \\
\hline $\mathrm{rt173/V173L}$ & LAM & 0.31 & 0.28 & 0.29 & 0.24 & 0.26 & 0.27 & $0.28 \pm 0.24$ \\
\hline \multicolumn{9}{|l|}{$\mathrm{rt181/}$} \\
\hline \multicolumn{9}{|l|}{ rt184/ } \\
\hline $\mathrm{T} 184 \mathrm{~A}$ & ETV & 0.96 & 0.98 & 0.99 & 0.92 & 0.91 & 0.94 & $0.95 \pm 0.32$ \\
\hline $\mathrm{T} 184 \mathrm{~S}$ & ETV & 0.5 & 0.49 & 0.51 & 0.50 & 0.48 & 0.58 & $0.51 \pm 0.01$ \\
\hline $\mathrm{rt} 202 / \mathrm{S} 202 \mathrm{G}$ & ETV & 0.51 & 0.53 & 0.54 & 0.54 & 0.52 & 0.53 & $0.53 \pm 0.11$ \\
\hline \multicolumn{9}{|l|}{ rt204/ } \\
\hline M204V & LAM/ETV & 0.63 & 0.63 & 0.54 & 0.61 & 0.57 & 0.63 & $0.60 \pm 0.27$ \\
\hline
\end{tabular}

Values are percentages.

namics assessed by ultra-deep sequencing and the clinical course of the infection has been described in patients with chronic hepatitis C treated with NS3-4 protease inhibitors [22, 23]. In our study, the analysis focused on nine well-known amino acid positions in the HBV polymerase gene that are associated with NA-resistant mutations. Because no drug-resistant mutations were detected with capillary sequencing, it is reasonable to assume that there were no mutations before treatment commencement. However, with deep sequencing, we detected several major drug-resistant mutations, including rtI169T and $\mathrm{rtM} 250 \mathrm{~V}$ conferring resistance to ETV, $\mathrm{rtV} 173 \mathrm{~L}$ to LAM, rtL180M to LAM/ETV, rtA181T to LAM/ADV/ LdT, rtA181V to ADV/LdT, rtT184A/S to ETV, rtS202G to ETV, rtM204V/I to LAM/ETV/LdT, and rtN236T to $\mathrm{ADV}$. The frequencies of these mutations ranged from 0.1 to $1.06 \%$ in all six samples obtained from Indonesian treatment-naïve patients with CHB (table 2). One should be careful about what threshold to use to define a clinically meaningful population. In recent studies, minority variants were defined as differences greater than 0.5 and $1.0 \%$ of mutations detected by deep sequencing [24, 25]. In this study, the proportions of the total numbers of reads containing mutations I169L/M, S202R, M204I/L or $\mathrm{N} 236 \mathrm{~S}$ were $>1.0 \%$.

Interestingly, we found no significant differences in the mutation frequencies between the chronic asymptomatic patients and the patients with advanced liver disease $(\mathrm{p}>$
0.05; table 4). The mutation profiles revealed that these major NA-resistant mutations were present before treatment commenced and that the mutation profiles of all 6 patients were similar. In comparison with earlier studies using deep sequencing, the mutational profiles were somehow different. A study from Korea reported that minor populations present in $>1 \%$ of viral quasispecies were detected in I169L, L180M and S202G in treatment-naïve patients [11], and a study from the USA revealed other mutational profiles including V173L, T184S and S202G [26]. Mutational profile differences depend on the genotype differences. In general, it was thought that clinical outcomes and prognoses differed among HBV genotypes and subgenotypes. HBV genotype B is associated with earlier HBeAg seroconversion and better response to interferon therapy than genotype $C[27,28]$. Whereas HBV in our study was genotype $\mathrm{B}$, other studies from Korea and the USA were genotypes $C$ and $G$, respectively $[11,26]$.

It had been unclear whether genomic variations contributed to the emergence of preexisting NA-resistant mutations. A recent report using deep sequencing revealed that these preexisting mutations were related to therapeutic discontinuation [24]. The next-generation sequencer was first introduced in 2005 and represents a significant advance in DNA sequencing. This method reads several million to billion short DNA fragments per run [29] and more than $1 \mathrm{~Gb}$ of the genome can be read in one run [30, 31]. Although next-generation sequencing will inevitably 
Table 3. Previously unreported mutations at nine positions associated with NA resistance detected with next-generation sequencing

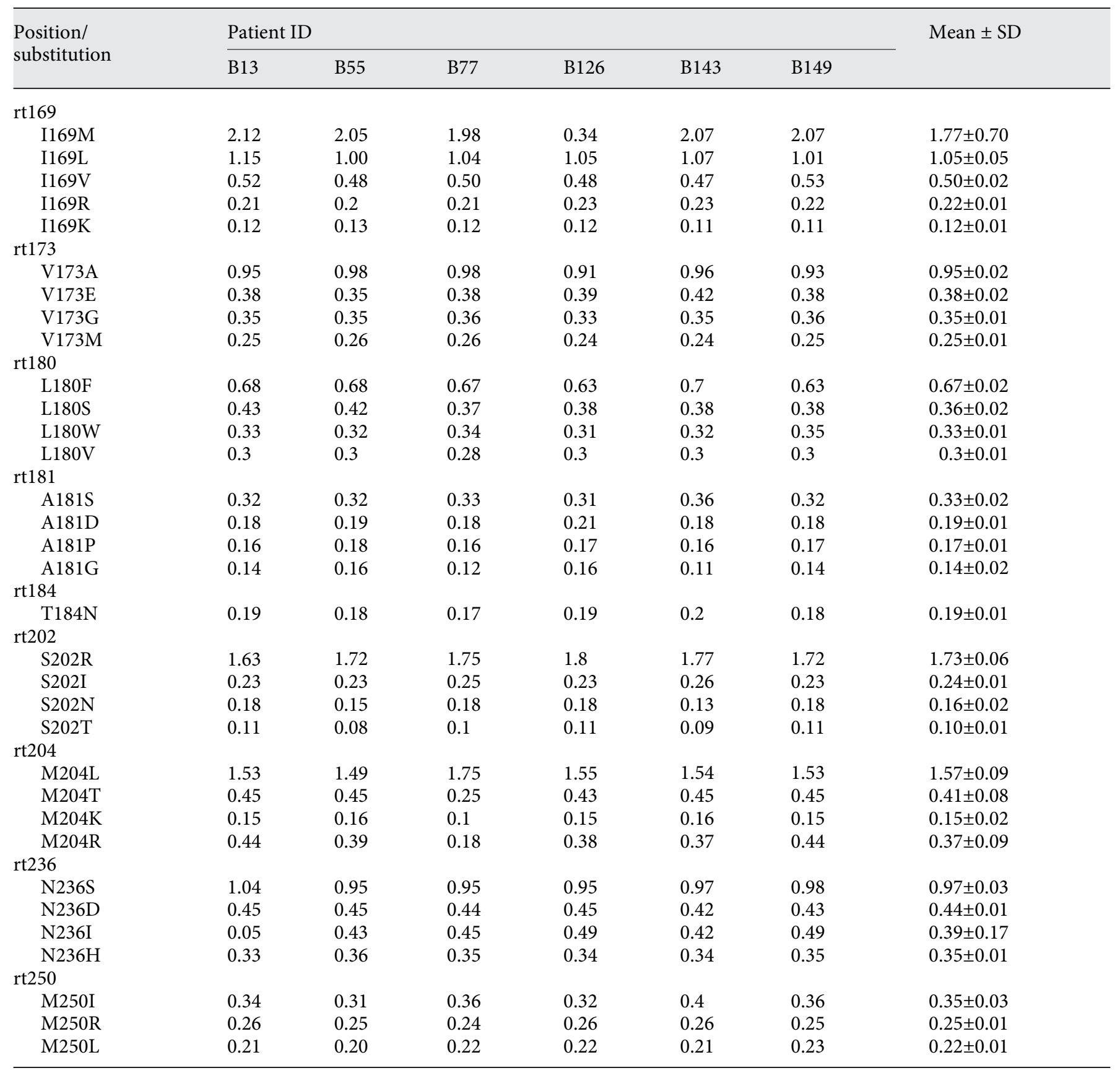

Values are presented as percentages.

make a significant contribution to human genomics, it is also effective in the detection of mutant populations occurring at low frequencies in specific viral genomes. In our study, the method sequenced more than 100,000 DNA fragments, allowing detailed analyses. Frequencies of
$1-2 \%$ for the substitutions L180M or M204V/I in pretreatment sequences were reported for patients who subsequently developed resistance to $\operatorname{LAM}[11,24]$. Therefore, a frequency of approximately $1 \%$ for the preexisting mutations M204I (conferring resistance to LAM/LdT) and 
Table 4. NA-resistant mutations in treatment-naïve patients with HBV according to clinical conditions

\begin{tabular}{|c|c|c|c|c|}
\hline $\begin{array}{l}\text { Position/ } \\
\text { substitution }\end{array}$ & NA resistance & $\begin{array}{l}\text { Asymptomatic } \\
\mathrm{CHB}, \%\end{array}$ & $\begin{array}{l}\text { Advanced } \\
\text { liver disease, \% }\end{array}$ & $\mathrm{p}$ value \\
\hline rt169/I169T & ETV & 0.193 & 0.187 & 0.23 \\
\hline rt173/V173L & LAM & 0.280 & 0.275 & 0.67 \\
\hline $\mathrm{rt180/L180M}$ & LAM/ETV & 0.120 & 0.123 & 0.19 \\
\hline \multicolumn{5}{|l|}{$\mathrm{rt181}$} \\
\hline A181T & $\mathrm{LAM} / \mathrm{ADV} / \mathrm{LdT}$ & 0.330 & 0.342 & 0.28 \\
\hline A181V & $\mathrm{ADV} / \mathrm{LdT}$ & 0.360 & 0.363 & 0.72 \\
\hline \multicolumn{5}{|l|}{$\mathrm{rt} 184$} \\
\hline $\mathrm{T} 184 \mathrm{~A}$ & ETV & 0.970 & 0.930 & 0.14 \\
\hline $\mathrm{T} 184 \mathrm{~S}$ & ETV & 0.523 & 0.493 & 0.49 \\
\hline rt202/S202G & ETV & 0.533 & 0.523 & 0.35 \\
\hline \multicolumn{5}{|l|}{ rt204 } \\
\hline M204V & LAM/ETV & 0.623 & 0.595 & 0.97 \\
\hline M204I & $\mathrm{LAM} / \mathrm{LdT}$ & 0.890 & 1.055 & 0.33 \\
\hline rt236/N236T & $\mathrm{ADV}$ & 0.667 & 0.68 & 0.15 \\
\hline $\mathrm{rt} 250 / \mathrm{M} 250 \mathrm{~V}$ & ETV & 0.340 & 0.35 & 0.72 \\
\hline
\end{tabular}

T184A (to ETV) might predict the emergence of mutations conferring resistance to NAs in these patients.

In conclusion, deep sequencing is an effective method to detect minor populations of antiviral drug-resistant mutations in treatment-naïve patients with CHB. Therefore, deep sequencing is a useful method for predicting the future emergence of antiviral drug-resistant HBV during long-term NA therapy. However, the threshold of a clinically meaningful population must be evaluated in future studies. This study shows that the profiles of NAresistant mutations in treatment-naïve patients with HBV genotype B3 differ from those in similar studies of genotype $C$ patients [11]. Nevertheless, our findings suggest that the genomic variations in HBV might play a crucial role in the subsequent evolution of NA resistance.

\section{Acknowledgements}

The writers would like to thank Catharina Triwikatmani, MD, Neneng Ratnasari, MD, Sutanto Maduseno, MD, Putut Bayu Purnama, MD, and Prof. Siti Nurdjanah, MD, for their help with collecting samples. This study was supported by a Grant-in-Aid from the Japan Initiative for Global Research Network on Infectious Disease (J-GRID) Program of the Ministry of Education, Culture, Sports, Science and Technology, Japan, a SATREPS Grant from the Japan Science and Technology Agency and the Japan International Cooperation Agency, and by the Ministry of Health, Labour, and Welfare of Japan (H25-general-008).

\section{Disclosure Statement}

The authors have no conflicts of interest to declare.

\section{References}

1 Lai CL, Ratziu V, Yuen MF, Poynard T: Viral hepatitis B. Lancet 2003;362:2089-2094.

- Sastrosoewignjo RI, Sandjaja B, Okamoto H: Molecular epidemiology of hepatitis B virus in Indonesia. J Gastroenterol Hepatol 1991;6: 491-498.

3 Liaw YF, Sung JJ, Chow WC, Farrell G, Lee CZ, Yuen H, Tanwandee T, Tao QM, Shue K, Keene ON, Dixon JS, Gray DF, Sabbat J: Lamivudine for patients with chronic hepatitis $\mathrm{B}$ and advanced liver disease. N Engl J Med 2004;351:1521-1531.

4 Matsumoto A, Tanaka E, Rokuhara A, Kiyosawa K, Kumada H, Omata M, Okita K,
Hayashi N, Okanoue T, Iino S, Tanikawa K: Efficacy of lamivudine for preventing hepatocellular carcinoma in chronic hepatitis B: a multicenter retrospective study of 2,795 patients. Hepatol Res 2005;32:173-184.

5 Chang TT, Lai CL, Chien RN, Guan R, Lim SG, Lee CM, Ng KY, Nicholls GJ, Dent JC, Leung NW: Four years of lamivudine treatment in Chinese patients with chronic hepatitis B. J Gastroenterol Hepatol 2004;19:12761282.

6 Colonno RJ, Rose R, Baldick CJ, Levine S, Pokornowski K, Yu CF, Walsh A, Fang J, Hsu M, Mazzucco C, Eggers B, Zhang S, Plym M,
Klesczewski K, Tenney DJ: Entecavir resistance is rare in nucleoside naive patients with hepatitis B. Hepatology 2006;44:1656-1665.

7 Hadziyannis SJ, Tassopoulos NC, Heathcote EJ, Chang TT, Kitis G, Rizzetto M, Marcellin P, Lim SG, Goodman Z, Ma J, Brosgart CL, Borroto-Esoda K, Arterburn S, Chuck SL: Long-term therapy with adefovir dipivoxil for HBeAg-negative chronic hepatitis B for up to 5 years. Gastroenterology 2006;131:17431751.

8 Inada M, Yokosuka O: Current antiviral therapies for chronic hepatitis B. Hepatol Res 2008;38:535-542. 
9 Cane PA, Mutimer D, Ratcliffe D, Cook P, Beards G, Elias E, Pillay D: Analysis of hepatitis $B$ virus quasispecies changes during emergence and reversion of lamivudine resistance in liver transplantation. Antivir Ther 1999;4:7-14.

10 Girones R, Miller RH: Mutation rate of the hepadnavirus genome. Virology 1989;170: 595-597.

11 Kim do Y, Chang HY, Lim SM, Kim SU, Park JY, Kim JK, Lee KS, Han KH, Chon CY, Ahn SH: Quasispecies and pre-existing drug-resistant mutations of hepatitis B virus in patients with chronic hepatitis B. Gut Liver 2013;7: 329-334.

$\checkmark 12$ Nishijima N, Marusawa H, Ueda Y, Takahashi K, Nasu A, Osaki Y, Kou T, Yazumi S, Fujiwara T, Tsuchiya S, Shimizu K, Uemoto $\mathrm{S}$, Chiba T: Dynamics of hepatitis B virus quasispecies in association with nucleos(t)ide analogue treatment determined by ultra-deep sequencing. PLoS One 2012;7:e35052.

-13 Abe A, Inoue K, Tanaka T, Kato J, Kajiyama N, Kawaguchi R, Tanaka S, Yoshiba M, Kohara M: Quantitation of hepatitis B virus genomic DNA by real-time detection PCR. J Clin Microbiol 1999;37:2899-2903.

14 Sugauchi F, Mizokami M, Orito E, Ohno T, Kato H, Suzuki S, Kimura Y, Ueda R, Butterworth LA, Cooksley WG: A novel variant genotype $C$ of hepatitis B virus identified in isolates from Australian Aborigines: complete genome sequence and phylogenetic relatedness. J Gen Virol 2001;82:883-892.

-15 Tamura K, Dudley J, Nei M, Kumar S: MEGA4: Molecular Evolutionary Genetics Analysis (MEGA) software version 4.0. Mol Biol Evol 2007;24:1596-1599.

16 Cao GW: Clinical relevance and public health significance of hepatitis $B$ virus genomic variations. World J Gastroenterol 2009;15:57615769.
Fung J, Lai CL, Seto WK, Yuen MF: Nucleoside/nucleotide analogues in the treatment of chronic hepatitis B. J Antimicrob Chemother 2011;66:2715-2725.

18 Margeridon-Thermet S, Shulman NS, Ahmed A, Shahriar R, Liu T, Wang C, Holmes SP, Babrzadeh F, Gharizadeh B, Hanczaruk B, Simen BB, Egholm M, Shafer RW: Ultra-deep pyrosequencing of hepatitis $B$ virus quasispecies from nucleoside and nucleotide reversetranscriptase inhibitor (NRTI)-treated patients and NRTI-naive patients. J Infect Dis 2009;199:1275-1285.

19 Solmone M, Vincenti D, Prosperi MC, Bruselles A, Ippolito G, Capobianchi MR: Use of massively parallel ultradeep pyrosequencing to characterize the genetic diversity of hepatitis $B$ virus in drug-resistant and drug-naive patients and to detect minor variants in reverse transcriptase and hepatitis B S antigen. J Virol 2009;83:1718-1726.

20 Mese S, Arikan M, Cakiris A, Abaci N, Gumus E, Kursun O, Onel D, Ustek D, Kaymakoglu S, Badur S, Yenen OS, Bozkaya E: Role of the line probe assay INNO-LiPA HBV DR and ultradeep pyrosequencing in detecting resistance mutations to nucleoside/nucleotide analogues in viral samples isolated from chronic hepatitis B patients. J Gen Virol 2013;94: 2729-2738.

21 Yousif M, Bell TG, Mudawi H, Glebe D, Kramvis A: Analysis of ultra-deep pyrosequencing and cloning based sequencing of the basic Core Promoter/Precore/Core region of hepatitis B virus using newly developed bioinformatics tools. PLOS One 2014;9:e95377.

22 Akuta N, Suzuki F, Seko Y, Kawamura Y, Sezaki H, Suzuki Y, Hosaka T, Kobayashi M, Hara T, Saitoh S, Arase Y, Ikeda K, Kumada $\mathrm{H}$ : Emergence of telaprevir-resistant variants detected by ultra-deep sequencing after triple therapy in patients infected with HCV genotype 1. J Med Virol 2013;85:1028-1036.

23 Hiraga N, Imamura M, Abe H, Hayes CN, Kono T, Onishi M, Tsuge M, Takahashi S, Ochi H, Iwao E, Kamiya N, Yamada I, Tateno C, Yoshizato K, Matsui H, Kanai A, Inaba T, Tanaka S, Chayama K: Rapid emergence of telaprevir resistant hepatitis $\mathrm{C}$ virus strain from wildtype clone in vivo. Hepatology 2011;54:781-788
24 Margeridon-Thermet S, Svarovskaia ES, Babrzadeh F, Martin R, Liu TF, Pacold M, Reuman EC, Holmes SP, Borroto-Esoda K, Shafer RW: Low-level persistence of drug resistance mutations in hepatitis B virus-infected subjects with a past history of lamivudine treatment. Antimicrob Agents Chemother 2013;57:343-349.

25 Han Y, Zhang Y, Mei Y, Wang Y, Liu T, Guan Y, Tan D, Liang Y, Yang L, Yi X: Analysis of hepatitis $B$ virus genotyping and drug resistance gene mutations based on massively parallel sequencing. J Virol Methods 2013;193: 341-347.

26 Margeridon-Thermet S, Shulman NS, Ahmed A, Shahriar R, Liu T, Wang C, Holmes SP, Babrzadeh F, Gharizadeh B, Hanczaruk B, Simen BB, Egholm M, Shafer RW: Ultra-deep pyrosequencing of hepatitis $B$ virus quasispecies from nucleoside and nucleotide reversetranscriptase inhibitor (NRTI)-treated patients and NRTI-naive patients. Infect Dis 2009;199:1275-1285.

27 Chu CJ, Hussain M, Lok AS: Quantitative serum HBV DNA levels during different stages of chronic hepatitis B infection. Hepatology 2002;36:1408-1415.

28 Wai CT, Chu CJ, Hussain M, Lok AS: HBV genotype $\mathrm{B}$ is associated with better response to interferon therapy in $\mathrm{HBeAg}^{+}$chronic hepatitis than genotype C. Hepatology 2002;36: $1425-1430$.

29 Margulies M, Egholm M, Altman WE, et al: Genome sequencing in microfabricated highdensity picolitre reactors. Nature 2005;437: 376-380.

30 Ansorge WJ: Next-generation DNA sequencing techniques. Nat Biotechnol 2009;25:195203

31 Metzker ML: Sequencing technologies - the next generation. Nat Rev Genet 2010;11:3146. 